\title{
When the Flower Wilts: Stigmas of Mental Illnesses in Indonesia
}

\author{
Shella Novia Herada
}

English Department, Faculty of Languages and Literature, Petra Christian University, Siwalankerto 121 131, Surabaya 60236, Indonesia

E-mail: shellanovia@gmail.com

\begin{abstract}
In Indonesia, mental illnesses, or more specifically, depression, is still seen as a moral failure, a failure to conform in society due to a faulty moral upbringing. However, little spotlight is given towards the immediate family of a sufferer, how a sufferer places burdens on their family in terms of economy, psychology, and social life, in addition to the burden of sympathy as the result of having to put the needs of someone else above onself. To depict such suffering and help make it more visible, I created a story, written from the perspective of someone close to a sufferer, to show how the immediate family also suffers from the negative stigma attached to a sufferer.
\end{abstract}

Keywords: sufferer, burden of sympathy, depression.

\section{INTRODUCTION}

Depression is a result of a person's interactions with their environment. Negative events in life, such as losing one's job, losing one's best friend, and repeated strings of failures remove sources of positive reinforcements in one's life, resulting to inactivity. Some develop a maladaptive behaviour, a situation where one turns the sympathy of friends, relatives, and loved ones as a main source of reinforcement by weeping, complaining and talking to suicide. However, this, in turn, feeds a downward spiral as their close peers become alienated by the constant negativity, and thus forcing the depressed to find more places to vent and feed their need for this unhealthy form of reinforcement (1980, p.322).

I have experienced how devastating mental illness can be, as I suffered from depression for a few months. During that time, it felt as if energy has been sapped away from my body and I felt tired the moment I woke up, struggling to even gather the required motivation to start the day. This goes on for a few months, and as I was unable to tell my parents about my current predicament to not worry them, I had to resort to using self-help books, writing, and reading to cope with it. As a side effect, I partially neglected my responsibilities, as everything felt like it required far more effort to do than it actually should, and I had bouts of crying at random times, sometimes even in the middle of the night. Later on I realized that my struggle was shorter than most, as people have to struggle against depression for years or most of their life. But during the short time, I could feel the hopelessness coupled with the fear of stigma from the neighbours, society, and the people around me.

In addition, what finally motivates me to write about this is the treatment of the depressed in Indonesia. In the broadcasted Facebook suicide case back in 2017, many dared him to go and stick his neck on the rope, calling him names and insulting him. That was not what concerned me, but what concerned me was the fact that the broadcaster answered the dare and ended up taking the plunge, and the devastation of the wife was all over the news as a result. This made me realize that even though depression and suicide is a serious matter, many in social media still treat it like a joke and will not realize the gravity of the problem until it is too late, some even treating those who express desire to die as 'having no guts', 'a chicken', or many other names 
that exacerbate the feeling of being useless if they are not brave enough to 'follow their words' and actually kill themselves.

To depict the effects of depression towards the immediate family of a sufferer within my story, I accumulated several researches to build a theoretical framework that is split into three parts. The first one, economic effects of depression, encompasses the direct and indirect costs. Direct costs are the cost of therapy, medications, sessions, transportations, hospitalization and/or institutionalizations, while indirect costs cover the costs of the loss of productive time from depressive episodes, hospitalizations, and death due to suicide, added with $6 \%$ to account for the inflation during said lost time according to Alan Stoudemire (1986, p.388)

After the economic effects, the second theory establishes the social impacts of depression, both towards the family members themselves and towards how society views the family members. According to Coyne (1987, p.347), people who lived with a survivor or sufferer of depression experiences interpersonal distress, mostly due to the burden of sympathy from putting another before oneself. Burden of sympathy results in hopelessness, lack of will, fatigue, and worry, to the point that $40 \%$ of those people qualify for psychological treatment themselves. On average, those who lived with a survivor or a sufferer has three points of distress lower than the sufferer or survivor, showing that mental illness in general affects the family long after the sufferer passed their depressive episodes. This theory is used to establish some of the problems. Even though the exact numbers aren't shown, some plot points rely on the fact that treatments for a sufferer is expensive.

In addition to the impacts towards the family. according to Martin, Pescosolido, and Tuch (2000, p.208), people in public view those with mental illness and those associated with said sufferer with fear and dislike, due to the persisting view that depression is not a treatable disease, but a moral flaw, caused by individual factors such as 'how the person was raised' or 'bad character', causing the public to avoid interaction with those associated with them. However, even if those factors are controlled or hidden, people will still tend to avoid those with the vignette 'mental illness' attached to them. This preference towards social distance extends across all ages and demographic types, a testament to the degree of dangerousness people view a sufferer and those associated with them. This theory forms the core of my main character's bullying related problem. Due to the view that those with mental illness is seen as morally flawed, the implication is that those associated with a sufferer carry similar moral flaws as well.

Last but not least, is the psychological effects of depression. According to Miller, (2000, p.539) a family containing one sufferer carries an increased risk of family dysfunction and marital discords. These reduces the likelihood of the sufferer's recovery and even increase the risks of relapse, an occurrence that happens across all ages and across all degrees of severity, with no link towards demograpic or severity variations. However, the risks of relapse is linked to the severity of the depressive disorder, and studies have shown that sufferers who displays longer episode of depressions has a higher risk of relapse. Additionally, according to Winokur (1972, p.5), he burden of taking care of a sufferer results in distress, causing the mental health of the family members to deteriorate as well. If this deterioration continues on, it can manifest in several ways, inculding symptoms of alcoholism or substance abuse, sociopathy, amnesia, or even severe phobias. This theory is used to form the basis of Camellia's descent and change of personality.

According to Coid \& Farrington (2003), anti-Social Personality Disorder (ASPD) or sometimes called sociopathy, is a mental condition in which a person shows no regard for right and wrong. They manipulate, antagonize, and treat others harshly, without guilt or remorese, even finding justifications or shift the blame for their actions. Several of the defining symptoms for ASPD 
includes the callous unconcern towards the feelings of others, irresponsibility that persist through repeated punishments, inability to maintain relationships, low tolerance for frustrations, and last but not leasts, the pronounced readiness to blame others or rationalize themselves in the aftermath of a conflict.

After choosing the theoretical framework I needed to construct the story, the next theory I need is my genre (naturalism) and chosen modes of expression (epistolary novel). According to Encyclopedia Britannica (2014), naturalism is "an approximation of truth, a mimetic art intended to portray, mirror, and represent the world as it objectively appears." Naturalism was chosen due to the lack of true antagonist figure in the genre. In place of an antagonist, naturalism relies on circumstances that can naturally happen in life to provide a sense of conflict. In other words, the characters become a victim of what the circumstances around them decide. Epistolary novel, according to Encyclopaedia Britannica (1998), is a novel written as a series of documents. Letters are the most common, but as technology marches on and the internet become more widespread, it can also take the form of diary entries, newspaper clippings, chat logs, e-mails, videos, or even pictures or receipts.

As this story is partially based of my experience, yet the established narrator's position is not in the point of view of someone who is a sufferer, I used what Immanuel Kant (1987) refer as 'disinterested delight', or 'aesthetic distance' in literary terms. It refers to the psychological distance between the narrator and the character, preventing the narrator from taking the influences of the author's life and lose the unique position of being an observer towards the plight of a sufferer.

\section{METHOD}

To create this Creative Thesis Project, I gathered some theories and split them into the three theories mentioned above, and with the help of my advisor, the theories become the basis of the worldbuilding and plot of my story. Other than the three theories, I also did some unofficial interviews to create the small details to make the world seem more real, such as the taste of medicine, the aftereffects, and little things that can't be gathered from secondary data alone.

The next step is creating the story. After my theoretical framework is approved, I started creating the story and divided it into three arcs, the beginning, where Camellia suffers, the middle, where Camellia starts to use increasingly underhanded tactics to take revenge and make herself feel as if her actions are justified, and the ending, where his brother, as the sufferer, committed suicide and woke up after the span of several weeks, but also underlining how Camellia, the narrator, did not come out unscathed after the ordeal of bullying from the society and her myriad of problems.

Next is the small details. After the three arcs are approved by my advisor, I used social media apps to contact five friends who is a survivor or a sufferer and ask them to describe their experiences. From their stories, the aftereffects of medicines that doesn't work, the different side effects of medicines, and the effect of not taking medicines are created. The effects depicted range from being full of energy for some time until finally crashing, the feelings of numbness, tiredness, and general inability to do anything. In particular, the numbness and tiredness from the medicine's side effect becomes a plot point in the midpoint to trigger Morgan's suicide, kickstarting the third and the final act.

\section{CONCLUSION}

From this work, the writer would like to show that not only depression sufferers face negative stigma, their family also has various burdens to deal with, from the more mundane such as how 
the family members of the sufferers has to cover material costs of treatment, to the hidden, more or less unseen psychological problems that results from extended periods of burdening oneself with the burden of a suffering relative and family member.

To achieve this, the writer used various theories to attempt to demonstrate, split the effects of depression towards the family of a sufferer into three distinct aspects, and portray the three aspects over the course of the story, ranging from treatment costs to the stigmas. The theories used in the creative work has also helped the writer to correct some of their preconceptions about mental illness, understand the burden of sympathy not as a sufferer, but as someone who is close to a sufferer, and use said knowledge to show the readers with story as the medium.

The writer hopes that the burdens of taking care of a sufferer becomes more well-understood by the general mass. The pervalence of literature written from the perspective of a sufferer has brought more awareness, however it also indirectly relegates the burdens a sufferer's immediate family has to endure to the background. Since this work relies mostly on theories, with interviews only used as background knowledge to demonstrate the effects of the antidepressants, the writer hopes that one day there will be more literature utilizing similar concepts, but with more personal accounts in order to create a more accurate portrayal,

\section{REFERENCES}

Coid, J. W., \& Farrington, D. P. (2003). Early Prevention of Adult Antisocial Behavior. Cambridge University Press.

Coyne, J. C. (1987). Living With a Depressed Person. Journal of Consulting and Clinical Psychology, 347-351.

Gerintya, S. (2017, March 18). Statistik Bunuh Diri dan Darurat Kesehatan Mental - Tirto.id. Retrieved from Tirto.id: https://tirto.id/statistik-bunuh-diri-dan-darurat-kesehatanmental-ck1u

Kant, I. (1987). Critique of Aesthetic Judgement. Indianapolis: Hackett Publishing.

Lazarus, R. S. (1984). Stress, Appraisal, and Coping. New York: Springer.

Lewinsohn, P., Sullivan, M., \& Grosscup, S. (1980). Changing Reinforcing Events: An Approach to Treatment of Depression. Psychotherapy, Theory, Research, and Practice Volume 17, 322-344.

Martin, J. K., Pescosolido, B. A., \& Tuch, S. A. (2000). Of Fear and Loathing: The Role of 'Disturbing Behavior', Labels, and Causal Attributions in Shaping Public View Towards People With Mental Illness. Journal of Health and Social Behavior, 208-223.

Miller, I., McDermut, W., \& Gordon, K. C. (2000). Personality and Family Functioning in Families of Depressed Patients. Journal of Abnormal Psychology, 539 - 545.

Naturalism |art| Britannica.com. (2014, February 18). Retrieved from Encyclopaedia Britannica: https://www.britannica.com/topic/naturalism-art

Stoudemire, A. (1986). The Economic Burden of Depression. 388-398.

The Editors of Encyclopaedia Britannica. (1998, July 20). Naturalism: Encyclopaedia Britannica. Retrieved from Encyclopaedia Britannica: http://www.britannica.com/topic/naturalism-art

Winokur, G. (1972). Depression Spectrum Disease: Description and Family Study. Comprehensive Psychiatry, 5-7. 